\title{
Genetic counselling of young women with breast cancer for Li-Fraumeni syndrome: a nationwide survey on the experiences and attitudes of genetics professionals
}

\author{
J. J. Bakhuizen ${ }^{1} \cdot$ M. E. Velthuizen ${ }^{1} \cdot$ S. Stehouwer ${ }^{1}$ E. M. Bleiker ${ }^{2,3} \cdot$ M. G. Ausems ${ }^{1}$
}

Published online: 20 September 2018

(c) The Author(s) 2018

\begin{abstract}
Germline TP53 mutations are associated with an increased risk of early-onset breast cancer. Traditionally, it was not standard practice to offer TP53 genetic testing due to the low mutation detection rate and limited options regarding preventive screening. Recent guidelines recommend that all women diagnosed with breast cancer before the age of 31, irrespective of family history, should be offered TP53 genetic testing. This study aims to gain more knowledge on the attitudes and experiences among genetics professionals regarding the timing and content of genetic counselling of young breast cancer patients for Li-Fraumeni syndrome (LFS). We conducted a nationwide online survey among genetics professionals who provide cancer genetic counselling in the Netherlands. Fifty-seven professionals completed the questionnaire (response rate overall 54\%, clinical geneticists 70\%). Most respondents reported that they discuss the option of TP53 genetic testing-simultaneously with $B R C A 1 / 2$-during the initial counselling visit, especially in case of referral for treatment-focused genetic counselling. There was a general consensus about ten information items that should be discussed during counselling. Sixty-one percent of genetics professionals did not encounter difficulties in providing genetic counselling for LFS, but a substantial minority (29\%) did. This study offers valuable insight, which will be useful for clinical practice. Studies which address young breast cancer patients' attitudes and preferences regarding the timing and content of counselling are warranted to further determine the most appropriate genetic counselling strategy for these women.
\end{abstract}

Keywords Attitudes $\cdot$ Li-Fraumeni syndrome $\cdot$ Genetics professional $\cdot$ Breast cancer $\cdot$ Genetic testing

\section{Introduction}

Women in the Netherlands have a $12 \%$, or a 1 -in- 8 , lifetime risk of being diagnosed with breast cancer [1]. In 2017 almost 15,000 women have been diagnosed with breast cancer in the Netherlands [2]. The great majority $(\sim 80 \%)$ was older than 50 years of age at the time of diagnosis, but 93 women $(0.6 \%)$ were younger than 30 years [2]. It is estimated that inherited mutations in breast cancer susceptibility

J. J. Bakhuizen

j.j.bakhuizen-2@umcutrecht.nl

1 Department of Genetics, University Medical Center Utrecht, PO Box 85090, 3508 AB Utrecht, The Netherlands

2 Family Cancer Clinic, Netherlands Cancer Institute, Amsterdam, The Netherlands

3 Division of Psychosocial Research and Epidemiology, The Netherlands Cancer Institute, Amsterdam, The Netherlands genes account for 5-10\% of all female breast cancers [3, 4]. Early age of onset is an indicator of genetic susceptibility [5]. In the Netherlands, all women diagnosed with breast cancer before the age of 40 are offered genetic testing for BRCA1, BRCA2 and CHEK2* 1100delC mutations [1, 6]. However, other cancer predisposition genes associated with early-onset breast cancer are known, including TP53 associated with Li-Fraumeni syndrome (LFS) [7].

LFS is a rare, inherited cancer syndrome characterized by a very high risk of a wide variety of early-onset neoplasms, including sarcoma, breast cancer, brain tumours and adrenocortical carcinoma [8]. Breast cancer is the most common cancer among female mutation carriers. The peak of incidence is under 30 years [9]. Highest TP53 mutation detection rates are reported in early-onset breast cancer patients with a family history suggestive of LFS or a personal history of an additional LFS-related tumour [10]. However, pathogenic TP53 sequence variants have also been described in women with apparently 'sporadic' 
early-onset breast cancer. Reported mutation detection rates in this population varied between 0 and $8.5 \%$ [11-16]. There was no consensus about offering TP53 genetic testing to all early-onset breast cancer patients, irrespective of family history $[10,12,13,15,16]$.

In the Netherlands, the general recommendation in 2005 and 2010 was to consider TP53 germline mutation testing in women with breast cancer before the age of 30 [17, 18]. However, due to the limited preventive strategies, this testing was usually only offered to those with a family history suggestive of LFS. According to the latest national consensusbased guideline, TP53 genetic testing should be offered to all breast cancer patients diagnosed before the age of 31 [19]. We hypothesized that the number of early-onset breast cancer patients counselled for LFS has increased over the last few years. However, little is known about genetics professionals' experiences and attitudes towards the genetic counselling of young women with breast cancer for LFS in the absence of a suggestive family history. Their opinion is exceedingly important since they actually provide the counselling. Therefore, we conducted a survey among genetics professionals who provide cancer genetic counselling in the Netherlands. We investigated their views regarding the timing and content of TP53 genetic counselling and the role of specialized professionals in psychosocial support. In addition, we collected nationwide laboratory records from all young breast cancer patients tested for TP53 mutations in the Netherlands in order to assess the prevalence of TP53 germline mutations. The results of this study are published separately [20]. In these two studies, we aimed to gain insight into the genetic counselling of young women with breast cancer for LFS in order to make clinical recommendations regarding the most appropriate counselling strategy for these women.

\section{Methods}

\section{Study design and procedure}

A cross-sectional online survey was conducted among all professionals (i.e. clinical geneticists, genetic counsellors and clinical geneticists-in-training) involved in cancer genetic counselling in the Netherlands. Study invitations with a link to the online survey were sent by mail. The initial time limit for completing the questionnaire was two weeks. Non-responders received up to two email reminders in an attempt to increase the response rate. Furthermore, key professionals (i.e. senior clinical geneticists from each hospital included in the study) were asked to encourage their colleagues to complete the survey. Data were collected in a 1 month period between March and April, 2017.

\section{Selection of participants}

To identify potential respondents, email addresses of clinical geneticists and genetic counsellors with special expertise in cancer genetics were collected by using the member registration of the Dutch Cancer Genetics Group (WKO; a national working group of the Dutch Society of Clinical Genetics on cancer genetics) and the member registration of the Dutch Association of Genetic Counsellors (NVGC). Hospitals were contacted for missing data. Email addresses of clinical geneticists-in-training with some experience in oncogenetic counselling were gathered during an education meeting. In total, the contact details of 106 genetics professionals were collected, including 50 clinical geneticists, 32 genetic counsellors and 24 clinical geneticists-in-training.

\section{Questionnaire development}

Questionnaire items were developed from unpublished results of a previous single-centre pilot study (Department of Genetics, University Medical Center Utrecht), including semi-structured interviews with genetics professionals, to identify key topics. A draft survey was designed using Research Online, a web-based secure and reliable survey tool that complies with the Good Clinical Practice guidelines for electronic data collecting [21]. The final questionnaire consisted of four sections. The first section comprised personal and professional demographics. The second section consisted of questions about the number of young breast cancer patients counselled for LFS by each respondent. Genetics professionals who have provided LFS genetic counselling for these counsellees were asked to fill in the third section of the questionnaire, including questions about providing genetic counselling for BRCA 1/2-, CHEK2 and TP53-mutations during the initial counselling visit. Professionals without experience in this field could directly continue with the fourth section of the questionnaire. This final section assessed participants' attitudes and views regarding the genetic counselling of young breast cancer patients for LFS. This included statements regarding information that could be provided for counselees (content of genetic counselling). Genetics professionals answered by providing a rating of importance to specific information. Other topics were the role of specialized professionals in psychosocial support and timing of TP53 genetic counselling and testing. Questions were all closed-ended except for questions asking respondents to elaborate on their close-ended answers. Five-point Likert-type scales were used to rate the level of agreement ( $1=$ strongly disagree, $2=$ disagree, $3=$ neutral, $4=$ agree, 
$5=$ strongly agree $)$ and importance $(1=$ not at all important, $2=$ of little importance, $3=$ moderately important, $4=$ important, $5=$ very important) in the majority of items assessing attitudes and views. Other questions utilized pre-given categorical response options or dichotomous responses ("yes" or "no").

\section{Data analysis}

Statistical analyses were performed using the IBM Statistical Package for the Social Sciences (SPSS) 21.0. Descriptive statistics (percentages) were used for the analysis of all close-ended questions (quantitative data). For data analysis and interpretation of questions assessing genetics professionals' attitudes, response categories for (agreement) Likert-type scale items were merged. Ratings 1 (strongly disagree) and 2 (disagree) were combined to construct a '(strongly) disagree' category, and ratings 4 (agree) and 5 (strongly agree) were merged to construct a corresponding '(strongly) agree' category. For interpretation of reported rates of importance regarding information items that could be discussed with counsellees, ratings 1 (very important) and 2 (important) were combined. In order to make recommendations for clinical practice, a threshold of $75 \%$

Table 1 Characteristics of respondents $(n=57)$

\begin{tabular}{lc}
\hline Variables and response categories & $\mathrm{n}(\%)$ \\
\hline Profession & \\
Clinical geneticist & $35(61 \%)$ \\
Genetic counsellor & $13(23 \%)$ \\
Clinical geneticist-in-training & $9(16 \%)$ \\
Experience (years) in oncogenetic counselling & \\
$<1$ & $4(7 \%)$ \\
$1-2$ & $8(14 \%)$ \\
$2-5$ & $7(12 \%)$ \\
$5-10$ & $8(14 \%)$ \\
$>10$ & $30(53 \%)$ \\
Sex & \\
Male & $9(16 \%)$ \\
Female & $48(84 \%)$ \\
\hline
\end{tabular}

of respondents who rated the information item as '(very) important' was considered to be 'consensus'.

\section{Results}

\section{Characteristics of respondents}

Fifty-seven of 106 genetics professionals (54\%) participated in the questionnaire (Table 1). The majority of respondents were clinical geneticists (61\%) and more than half of respondents (53\%) have worked in the field of oncogenetics for over 10 years. Response rates differed between professions and hospitals (data not shown) (“Appendix").

\section{Genetics professionals' experiences}

Ninety-six percent of respondents (55/57) have counselled at least one woman diagnosed with breast cancer before the age of 30 (Table 2). LFS was not discussed with all young breast cancer patients who were referred for cancer genetic counselling. Nonetheless, all professionals who have provided cancer genetic counselling for women with early-onset breast cancer have some experience in discussing LFS. Forty percent (23/57) of respondents have provided information about TP53 genetic testing to at least ten young breast cancer patients. Genetics professionals were asked for reasons for not discussing LFS with all women who were counselled for early-onset breast cancer. The most reported reasons were changes in national or hospital-based guidelines. Discussing LFS with all young breast cancer patients has not always been part of standard care. Previously, genetic testing for TP53 was only offered if a suggestive family history of LFS was present. Furthermore, two respondents preferred to wait for BRCA genetic test results before offering TP53 genetic testing. TP53 genetic testing is no longer indicated in case a $B R C A$ mutation is detected.

Seventy-three percent of professionals reported that, in general, they discuss the options for BRCA1/2, CHEK2 and TP53 during the initial counselling visit when women are referred for treatment-focused genetic counselling and testing (Table 3). Remaining respondents (27\%) noted that they
Table 2 Genetics professionals' experiences with the genetic counselling of women diagnosed with breast cancer under the age of 30 in general (I) and for LFS (II)

\begin{tabular}{lllllll}
\hline & \multicolumn{7}{l}{ Number of patients } & & \\
\cline { 2 - 7 } & 0 & $1-5$ & $5-10$ & $10-15$ & $15-20$ & $>20$ \\
\hline $\begin{array}{l}\text { I. Professionals who have } \\
\text { counselled young breast cancer } \\
\text { patients (n) }\end{array}$ & 2 & 15 & 12 & 11 & 7 & 10 \\
$\begin{array}{c}\text { II. Professionals who have dis- } \\
\text { cussed LFS with young breast } \\
\text { cancer patients (n) }\end{array}$ & - & 20 & 11 & 10 & 5 & 8 \\
\hline
\end{tabular}

LFS Li-Fraumeni syndrome 
Table 3 Genetics professionals' experiences regarding providing genetic counselling for BRCA 1/2, CHEK2 and TP53-mutations during the initial counselling visit

\begin{tabular}{|c|c|c|c|c|c|}
\hline & $\mathrm{n}$ & Yes & \multicolumn{2}{|c|}{ Sometimes } & No \\
\hline \multicolumn{6}{|l|}{ Do you discuss the options of $B R C A 1 / 2, C H E K 2$ and TP53-GT during the initial counselling visit? } \\
\hline A. In case of referral for treatment-focused genetic counselling and testing ${ }^{a}$ & 49 & $73 \%(36)$ & \multicolumn{2}{|c|}{$27 \%(13)$} & - \\
\hline B. In case of a regular referral & 54 & $58 \%(33)$ & \multicolumn{2}{|c|}{$33 \%(19)$} & $4 \%(2)$ \\
\hline Evaluation & $\mathrm{n}$ & (Totally) disagree & Neutral & (Tota & y) agree \\
\hline $\begin{array}{l}\text { In general I am able to provide sufficient information about clinical and genetic aspects of } \\
\text { BRCA1/2, CHEK2 and TP53-mutations during a single counselling visit }\end{array}$ & 54 & $9 \%(5)$ & $15 \%(8)$ & $76 \%$ & \\
\hline $\begin{array}{l}\text { In general I am able to pay enough attention to the decision making process for BRCA1/2, } \\
\text { CHEK2 and TP53-GT during a single counselling visit }\end{array}$ & 54 & $15 \%(8)$ & $24 \%(13)$ & $61 \%$ & \\
\hline $\begin{array}{l}\text { I have difficulties in providing accurate genetic counselling for BRCA 1/2, CHEK2 and } \\
\text { TP53 during a single counselling visit }\end{array}$ & 51 & $55 \%(28)$ & $18 \%(9)$ & $28 \%$ & \\
\hline
\end{tabular}

Sample size (n) is presented and varies per question due to missing data and because of the fact that some questions do not apply to all respondents. Percentages reflect the proportion of participants selecting the response category divided by the total number of respondents to the corresponding question or statement

LFS Li-Fraumeni syndrome, $B C$ breast cancer, $G T$ genetic testing

${ }^{a}$ Referral for treatment-focused genetic counselling and testing is indicated when decisions about primary breast cancer treatment could be impacted by genetic test results

sometimes discuss these three genetic tests during the first appointment. In case of a regular referral, fewer counsellors (58\%) provide genetic counselling for LFS during the initial visit.

\section{Evaluation}

Respondents were asked to evaluate their experiences. The majority of counsellors (76\%) (totally) agreed with the statement 'In general I am able to provide sufficient information about clinical and genetic aspects of BRCA1/2, CHEK2 and TP53-mutations during a single counselling visit.' Fewer participants $(61 \%)$ noted they were able to pay enough attention to the decision-making process. Approximately half of respondents (55\%) did not have difficulties providing accurate genetic counselling for BRCA1/2, CHEK2 and TP53 during a single visit. Fourteen genetics professionals (28\%; five clinical geneticists, four genetic counsellors and five clinical geneticists-in-training) experience difficulties in providing accurate genetic counselling for these four genes during a single visit.

\section{Genetics professionals' attitudes}

\section{Content of genetic counselling}

Genetics professionals rated the importance of 17 information items about LFS that could be discussed with young breast cancer patients (Table 4). Ten information items were rated as (very) important by more than $75 \%$ of participants. Of the category 'tumour spectrum items' all participants rated the following item as (very) important: 'explaining that several cancers in addition to breast cancer may occur in individuals with LFS'. Fewer participants (35\%) considered it important to mention the four most common tumour types in individuals with LFS. Providing information about the low TP53 mutation detection rate, as well as the high risk of developing cancer in individuals with LFS, was rated as important by every professional. Mentioning specific odds (expressed as percentages) of mutation detection rates and cancer risks was considered (very) important by respectively 33 and $26 \%$ of respondents. With regard to other information items, almost all participants considered discussing possible consequences for family members, limited screening options as well as the option of additional support by a psychosocial professional as (very) important. Fewer participants (35\%) considered mentioning the name of the genetic disorder to be important.

\section{Additional psychosocial support}

Genetics professionals were asked in which situation(s) additional support by a psychosocial professional (social worker or psychologist attached to the department of genetics) would be desirable. Respondents were allowed to choose more than one response category. The vast majority of respondents (88\%) reported that additional support by a psychosocial professional is advisable in case it is questionable whether the counsellee understands the implications of TP53 genetic testing (Table 5). Furthermore, doubts about performing TP53 genetic testing, detection of a TP53 mutation and problematic family communication were considered desirable indications for additional psychosocial support by more than two-thirds of respondents. In addition 
Table 4 Frequencies of genetics professionals' ratings of information items as important or very important $(n=57)$

\begin{tabular}{|c|c|c|}
\hline \multirow[t]{2}{*}{ During counselling, you should... } & \multicolumn{2}{|c|}{$\begin{array}{l}\text { (Very) } \\
\text { impor- } \\
\text { tant }\end{array}$} \\
\hline & $\mathrm{n}$ & $\%$ \\
\hline \multicolumn{3}{|l|}{ Tumour spectrum } \\
\hline Explain that several cancers in addition to breast cancer may occur in individuals with LFS & 57 & 100 \\
\hline Provide 1-3 examples of LFS-related cancers & 46 & 81 \\
\hline Mention the four most common tumour types in individuals with LFS & 25 & 44 \\
\hline \multicolumn{3}{|l|}{ Mutation detection rate } \\
\hline Tell that the TP53 mutation detection rate is (very) low & 57 & 100 \\
\hline Specify the TP53 mutation detection rate with a percentage & 19 & 33 \\
\hline \multicolumn{3}{|l|}{ Cancer risks } \\
\hline Explain that individuals with LFS are at high risk of developing cancer & 57 & 100 \\
\hline Explain that individuals with LFS are at increased risk of developing a second cancer & 45 & 79 \\
\hline Explain that individuals with LFS are at increased risk of developing multiple primary cancers & 42 & 74 \\
\hline Specify cancer risk in individuals with LFS with a percentage & 15 & 26 \\
\hline Tell that the overall lifetime cancer risk for women with LFS is higher than that for men & 11 & 19 \\
\hline \multicolumn{3}{|l|}{ Other information items } \\
\hline Discuss possible consequences for family members if a TP53 mutation is detected & 54 & 95 \\
\hline Mention there are limited screening options for TP53 mutation carriers & 53 & 93 \\
\hline Discuss the option of additional support by a psychosocial professional & 51 & 90 \\
\hline Explain that radiotherapy should be avoided in individuals with LFS & 49 & 86 \\
\hline Tell that TP53 mutation carriers are offered a whole-body MRI (within research context) & 47 & 83 \\
\hline Provide examples of possible reasons for or against performing TP53 genetic testing & 40 & 70 \\
\hline Mention the name of genetic disorder & 20 & 35 \\
\hline
\end{tabular}

LFS Li-Fraumeni syndrome, MRI magnetic resonance imaging
Table 5 Genetics professionals' opinions regarding additional psychosocial support $(\mathrm{n}=57)$

\begin{tabular}{lrr}
\hline $\begin{array}{l}\text { Additional support by a psychosocial professional } \\
\text { able... }\end{array}$ & is desir- & $\mathrm{n}$ \\
\hline $\begin{array}{l}\text { In case it is questionable whether the counsellee has fore- } \\
\text { seen the implications of TP53 GT }\end{array}$ & 50 & 88 \\
In case the counsellee is doubting about performing TP53 & 43 & 75 \\
GT & 42 & 74 \\
In case family communication is problematic & 39 & 68 \\
In case a TP53 mutation is detected & 18 & 32 \\
In case a TP53-VUS is detected & 10 & 18 \\
In case of family history highly suggestive for LFS & 3 & 5 \\
For all counsellees who are offered TP53 GT & 2 & 4 \\
For all women diagnosed with BC <30 years & 2 & 4 \\
In case the counsellee wants to become pregnant & &
\end{tabular}

$B C$ breast cancer, $G T$ genetic testing, $L F S$ Li-Fraumeni syndrome

${ }^{a}$ Social worker or psychologist

to the categorical response options provided, self-reported items included history of psychosocial disturbance/psychiatric disorder $(n=5)$ and patient's request for additional psychosocial support $(n=5)$. Only two percent of respondents agreed that all young breast cancer patients who are offered
TP53 genetic testing should receive additional support by a psychosocial professional before TP53 genetic testing is performed (Table 6, A).

\section{Timing of genetic counselling and testing}

Respondents were also asked about the extent of their agreement (or disagreement) with three statements about the timing of genetic counselling and testing for LFS (Table 6, B). The minority of respondents (22\%) agreed with the first statement 'The option of TP53 genetic testing should preferably be discussed after $B R C A$ genetic test results are known.' A similar number of participants agreed with the second statement ('In case of a regular referral...'). Less than one-third of respondents $(32 \%)$ agreed that, in case of a regular referral, TP53 genetic testing should preferably be performed after a second counselling visit. For all three statements, approximately one-fourth of respondents selected the 'neutral' response option.

\section{In general}

Almost all (96\%) respondents (totally) disagreed with the statement 'I (would) encounter difficulties in discussing the 
Table 6 Attitudes of genetics professionals regarding genetic counselling of women diagnosed with breast cancer $<30$ years for LFS

n (Totally) Neutral (Totally) agree disagree

A. Additional psychosocial support

All young BC patients who are offered diagnostic TP53 GT should receive additional support by a $\quad 56 \quad 71 \% \quad 27 \% \quad 2 \%$ psychosocial professional before TP53 GT is performed

B. Timing of genetic counselling and testing

The option of TP53 GT should preferably be discussed after BRCA GT results are known

In case of a regular referral, the option of TP53 GT should preferably be discussed after BRCA GT results are known

In case of a regular referral, TP53 GT should preferably be performed after a second counselling visit $\quad 56 \quad 43 \% \quad 25 \% \quad 32 \%$

C. In general

I (would) encounter difficulties in discussing the option of BRCA GT and possible consequences of a $\quad 56 \quad 95 \% \quad 2 \% \quad 4 \%$

I (would) encounter difficulties in discussing the option of TP53 GT and possible consequences of a $\quad 56 \quad 61 \% \quad 11 \% \quad 29 \%$ TP53 mutation with women diagnosed with $\mathrm{BC}<30$ years

Sample size (n) is presented and varies per question due to missing data. Percentages reflect the proportion of participants selecting the response category divided by the total number of respondents (per profession) to the corresponding statement

$L F S$ Li-Fraumeni syndrome, $B C$ breast cancer, $G T$ genetic testing

option of BRCA1/2 with young breast cancer patients'. Only two clinical-geneticists-in-training agreed with this statement (Table 6, C). More respondents (29\%) reported that they encounter difficulties in discussing the option of TP53 genetic testing. Nonetheless the majority (61\%) disagreed. Genetics professionals who reported that they encounter difficulties were asked to explain their responses. Table 7 shows the frequencies of reported reasons for encountering difficulties in providing genetic counselling of young breast cancer patients for LFS. Respondents were allowed to choose more than one response category. The most frequently noted reasons were 'limited screening options' $(n=25)$ and 'severity and diversity of tumour spectrum' $(n=21)$.

\section{Discussion}

To our knowledge, this is the first reported survey about the attitudes and experiences of genetics professionals regarding genetic counselling of young breast cancer patients for LFS. To summarize, most respondents reported that they discuss the option of TP53 genetic testing-simultaneously with $B R C A 1 / 2$-during the initial counselling visit, especially in case of referral for treatment-focused genetic counselling. Furthermore, there was a general consensus about ten information items that should be discussed with counsellees. Almost two-thirds of genetics professionals did not encounter difficulties in providing genetic counselling of young breast cancer patients for LFS. However, a substantial minority did.

\section{Clinical recommendations}

This study aimed to make recommendations for clinical practice regarding the content and timing of genetic counselling and indications for additional psychosocial support. Table 8 shows the ten information items about LFS that should be discussed with young breast cancer patients during pre-test counselling.

Almost all respondents indicated that it is important to discuss the option of additional support by a psychosocial professional during genetic counselling. However, the
Table 7 Frequencies of reported reasons for encountering difficulties in providing genetic counselling of young breast cancer patients for LFS $(n=56)$

\begin{tabular}{lcc}
\hline & $\mathrm{n}$ & $\%$ \\
\hline Limited screening options for TP53 mutation carriers & 25 & 45 \\
Severity and diversity of tumour spectrum in TP53 mutation carriers & 21 & 38 \\
The psychosocial distress that might be induced & 12 & 21 \\
Young age at diagnosis (before age 30) & 5 & 9 \\
Low TP53 mutation detection rate & 5 & 9 \\
Little experience in providing genetic counselling for LFS & 5 & 9 \\
\hline
\end{tabular}

LFS Li-Fraumeni syndrome 
Table 8 Information items about LFS that should be discussed during pre-test genetic counselling \begin{tabular}{l}
\hline Several cancers in addition to breast cancer may occur in individuals with LFS \\
\hline $1-3$ examples of LFS-related cancers \\
The TP53 mutation detection rate is (very) low \\
Individuals with LFS are at high risk of developing cancer \\
Individuals with LFS are at increased risk of developing a second cancer \\
Possible consequences for family members if a TP53 mutation is detected \\
There are limited screening options for TP53 mutation carriers \\
The option of additional support by a psychosocial professional \\
Radiotherapy should be avoided in individuals with LFS \\
TP53 mutation carriers are offered a whole-body MRI (within research context)
\end{tabular}

LFS Li-Fraumeni syndrome, MRI magnetic resonance imaging majority of genetics professionals disagree that all young breast cancer patients who are offered diagnostic TP53 genetic testing should receive this support before TP53 genetic testing is performed. These findings suggest that genetics professionals feel capable of identifying counsellees who need additional psychosocial support. Nonetheless, there seems to be general consensus among respondents $(\geq 75 \%)$ that additional support by a psychosocial professional should be provided in two specific situations. Firstly, in case it is questionable whether the counsellee has understood the implications of TP53 genetic testing, and secondly, in case the counsellee has doubts about performing TP53 genetic testing. Our results partly differ from recommendations from the Dutch patient association 'Stichting Diagnose Kanker' (SDK) and European Li-Fraumeni Families Foundation (ELFF), as mentioned in the medical standard 'Li-Fraumeni Syndroom'. A substantial minority of respondents (approximately one-third) did not consider 'the detection of a TP53 mutation' as an indication for specialized psychosocial support. Whereas, the medical standard recommends that specialized psychosocial counselling should always be provided in case a TP53 mutation is detected [22]. A plausible explanation for this discrepancy is that the majority of respondents were clinical geneticists who have been working in the field of oncogenetics for over 10 years.

\section{Difficulties in providing genetic counselling for LFS}

The results of our retrospective laboratory records review showed an increase in the number of early-onset breast cancer patients tested for TP53 germline mutations [20]. This suggests that TP53 genetic testing is being discussed with young breast cancer patients more often. Although, most respondents did not encounter difficulties in providing genetic counselling of young breast cancer patients for LFS, a substantial minority did. The most frequently noted reasons were limited screening options, severity and diversity of tumour spectrum and the psychosocial distress that might be induced.

In recent years, multiple suggestions for clinical surveillance of individuals with LFS have been proposed [7, 23-26]. In the Netherlands, TP53 mutations carriers are offered an annual surveillance program, including physical examination, blood tests, whole body MRI (WB-MRI) and breast MRI in female patients. Recently, the initial findings of this surveillance program were published [27]. Malignancies were detected in approximately $7 \%$ of individuals with LFS. This detection rate must be weighed against the limitations (e.g. many false-positive findings and additional diagnostic procedures). Furthermore, it is uncertain whether annual WB-MRI will improve the long-term prognosis of TP53 mutation carriers. Data on TP53 carriers' experiences with the annual surveillance program, including the psychosocial issues, are currently being collected.

A few studies have reported that a substantial proportion of individuals in families with TP53 mutations, irrespective of their carrier status, exhibit psychological distress [28-30]. However, to our knowledge, no studies have been published evaluating the psychosocial impact of discussing LFS with early-onset breast cancer patients. As 'sporadic' early-onset breast cancer patients lack a family history suggestive of LFS, they may experience different psychosocial issues. Studies which address young breast cancer patients' experiences regarding the genetic counselling for LFS are warranted, in order to gain insight into the psychosocial impact of this counselling and to help identify those individuals in need of professional psychosocial support.

\section{Limitations}

Although a large number of genetics professionals did participate in the questionnaire, the results of the survey might not be generalizable for all genetics professionals who provide cancer genetic counselling in the Netherlands. Forty-eight percent of eligible genetics professionals did not participate in the questionnaire and response rates differed 
between professions and hospitals. A detailed stratified analysis on profession was not possible due to the significant difference between the number of participants in each profession. Additionally, the possibility of a non-response bias cannot be excluded, as it is possible that professionals who have responded have stronger opinions than nonrespondents. However, all nine hospitals were represented in the group of respondents and this study covered all three professions that provide genetic counselling. The response rate among clinical geneticists (supervisors of genetic counsellors and genetics residents) was relatively high (70\%) and exceeded the mean response rate of $56 \%$ reported in a review of postal surveys conducted among healthcare professionals [31]. Furthermore, more than half of the respondents have extensive experience in providing cancer genetic counselling as they have been working in cancer genetic counselling for over 10 years.

\section{Conclusion}

The number of early-onset breast cancer patients tested for LFS has increased over the past years.

The results of our nationwide survey suggest that most genetics professionals discuss the option of TP53 genetic testing-simultaneously with BRCA $1 / 2$ and $C H E K 2$-during the initial counselling visit, especially in case of referral for treatment-focused genetic counselling. Our recommendations regarding the content of genetic counselling for LFS and indications for additional psychosocial support will be useful for clinical practice. Studies which address young breast cancer patients' experiences (including psychosocial impact) are needed to further determine the most appropriate genetic counselling strategy for these women.

\section{Compliance with ethical standards}

Conflict of interest The authors declare that they have no conflict of interest.

Ethical approval The Medical Research Ethical Committee concluded that the Medical Research Human Subject Acts (WMO) does not apply.

Open Access This article is distributed under the terms of the Creative Commons Attribution 4.0 International License (http://creativeco mmons.org/licenses/by/4.0/), which permits unrestricted use, distribution, and reproduction in any medium, provided you give appropriate
Table 9 Response rates per profession and hospital

\begin{tabular}{lccl}
\hline & Invitations (n) & $\begin{array}{l}\text { Respond- } \\
\text { ents (n) }\end{array}$ & $\begin{array}{l}\text { Response } \\
\text { rate }(\%)\end{array}$ \\
\hline Profession & & & \\
Clinical geneticist & 50 & 35 & 70 \\
Genetic counsellor & 32 & 13 & 41 \\
Clinical geneticist-in-training & 24 & 9 & 38 \\
Hospital & & & \\
AMC & 8 & 3 & 38 \\
AVL & 10 & 8 & 80 \\
Erasmus MC & 12 & 4 & 33 \\
LUMC & 14 & 8 & 57 \\
MUMC & 11 & 4 & 36 \\
Radboudumc & 17 & 9 & 53 \\
UMCG & 14 & 7 & 50 \\
UMCU & 12 & 9 & 75 \\
VUMC & 9 & 5 & 56 \\
Total & 106 & 57 & 54 \\
\hline
\end{tabular}

credit to the original author(s) and the source, provide a link to the Creative Commons license, and indicate if changes were made.

\section{Appendix}

See Table 9.

\section{References}

1. NABON (2017) Breast cancer, Dutch guideline. http://www.oncol ine.nl/borstkanker. Accessed 25 May 2018

2. Netherlands Comprehensive Cancer Organisation (IKNL) (2017) Dutch cancer Figs. 2017. http://www.cijfersoverkank er.nl/. Accessed 21 May 2018

3. Turnbull C, Rahman N (2008) Genetic predisposition to breast cancer: past, present, and future. Annu Rev Genomics Hum Genet 9:321-345. https://doi.org/10.1146/annurev.genom 9.081307.164339

4. Tung N, Lin NU, Kidd J et al (2016) Frequency of germline mutations in 25 cancer susceptibility genes in a sequential series of patients with breast cancer. J Clin Oncol 34(13):1460-1468. https://doi.org/10.1146/annurev.genom.9.081307.164339

5. Claus EB, Risch NJ, Thompson D (1990) Age at onset as an indicator of familial risk of breast-cancer. Am J Epidemiol 131(6):961-972. https://doi.org/10.1093/oxfordjournals.aje. a115616 
6. Adank MA, Hes FJ, van Zelst-Stams WAG et al (2015) CHEK2mutation in Dutch breast cancer families: expanding genetic testing for breast cancer. Ned Tijdschr Geneeskd 159:A8910

7. National Comprehensive Cancer Network (2018) NCCN Clinical Practice Guidelines in Oncology: genetic/familial high risk assessment: breast and ovarian (Version I.2018). https://www. nccn.org/professionals/physician_gls/pdf/genetics_screening. pdf (registration required). Accessed 21 May 2018

8. Schneider K, Zelley K, Nichols KE et al (1999) Li-Fraumeni syndrome. In: Adam MP, Ardinger HH, Pagon RA et al (eds) GeneReviews. University of Washington, Seattle. https://www. ncbi.nlm.nih.gov/books/NBK1311/. Accessed 11 Apr 2013

9. Bouaoun L, Sonkin D, Ardin M et al (2016) TP53 variations in human cancers: new lessons from the IARC TP53 database and genomics data. Hum Mutat 37(9):865-876. https://doi. org/10.1002/humu.23035

10. Tinat J, Bougeard G, Baert-Desurmont S et al (2009) 2009 version of the Chompret criteria for Li Fraumeni syndrome. J Clin Oncol 27(26):e108-e109. https://doi.org/10.1200/ JCO.2009.22.7967

11. Lalloo F, Varley J, Moran A et al (2006) BRCA1, BRCA2 and TP53 mutations in very early-onset breast cancer with associated risks to relatives. Eur J Cancer 42(8):1143-1150. https:// doi.org/10.1016/j.ejca.2005.11.032

12. Gonzalez KD, Noltner KA, Buzin CH et al (2009) Beyond Li Fraumeni syndrome: clinical characteristics of families with p53 germline mutations. J Clin Oncol 27(8):1250-1256. https://doi. org/10.1200/JCO.2008.16.6959

13. Ginsburg OM, Akbari MR, Aziz Z et al (2009) The prevalence of germ-line TP53 mutations in women diagnosed with breast cancer before age 30. Fam Cancer 8(4):563-567. https://doi.org/10.1007/ s10689-009-9287-z

14. Mouchawar J, Korch C, Byers T et al (2010) Population-based estimate of the contribution of TP53 mutations to subgroups of early-onset breast cancer: Australian Breast Cancer Family Study. Cancer Res 70(12):4795-4800. https://doi.org/10.1158/00085472.CAN-09-0851

15. McCuaig JM, Armel SR, Novokmet A et al (2012) Routine TP53 testing for breast cancer under age 30: ready for prime time? Fam Cancer 11(4):607-613. https://doi.org/10.1007/s1068 9-012-9557-z

16. Bougeard G, Renaux-Petel M, Flaman JM et al (2015) Revisiting Li-Fraumeni syndrome from TP53 mutation carriers. J Clin Oncol 33(21):2345-2352. https://doi.org/10.1200/JCO.2014.59.5728

17. Netherlands Foundation for the Detection of Hereditary Tumours (STOET) and the Dutch Society of Clinical Genetics (VKGN) (2005) Erfelijke tumoren: richtlijnen voor diagnostiek en preventie. Edition 2005

18. Netherlands Foundation for the Detection of Hereditary Tumours (STOET) and the Dutch Society of Clinical Genetics (VKGN) (2010) Erfelijke tumoren: richtlijnen voor diagnostiek en preventie. Edition 2010
19. Netherlands Foundation for the Detection of Hereditary Tumours (STOET) and the Dutch Society of Clinical Genetics (VKGN) (2017) Erfelijke tumoren: richtlijnen voor diagnostiek en preventie. Edition 2017

20. Bakhuizen JJ, Hogervorst FB, Velthuizen ME (2018) Early-onset sporadic breast cancer: an indication for routine TP53 germline mutation testing? (manuscript in submission)

21. UMC Utrecht Julius Centrum (2017) Research online. http://www. researchonline.info. Accessed 7 May 2017

22. Stichting Diagnose Kanker (SDK), European Li-Fraumeni Families Foundation (ELFF) (2014) Zorgstandaard Li-Fraumeni Syndroom. Edition 2014. http://www.zorginzicht.nl/bibliotheek/ 1l-fraumeni-syndroom/KwaliteitsstandaardenDocumenten/Zorgs tandaard-li-fraumeni.pdf. Accessed 10 May 2017

23. McBride KA, Ballinger ML, Killick E et al (2014) Li-Fraumeni syndrome: cancer risk assessment and clinical management. Nat Rev Clin Oncol 11(5):260-271. https://doi.org/10.1038/nrcli nonc. 2014.41

24. Villani A, Tabori U, Schiffman J et al (2011) Biochemical and imaging surveillance in germline TP53 mutation carriers with Li-Fraumeni syndrome: a prospective observational study. Lancet Oncol 12(6):559-567. https://doi.org/10.1016/S1470 -2045(11)70119-X

25. Villani A, Shore A, Wasserman JD et al (2016) Biochemical and imaging surveillance in germline TP53 mutation carriers with Li-Fraumeni syndrome: 11 year follow-up of a prospective observational study. Lancet Oncol 17(9):1295-1305. https://doi. org/10.1016/S1470-2045(16)30249-2

26. Kratz CP, Achatz MI, Brugieres L et al (2017) Cancer screening recommendations for individuals with $\mathrm{Li}-\mathrm{Fraumeni}$ syndrome. Clin Cancer Res 23(11):e38-e45. https://doi.org/10.1158/10780432.CCR-17-0408

27. Ruijs MWG, Loo CE, van Buchem CAJM, et al (2017) Surveillance of Dutch patients with Li-Fraumeni syndrome: the LiFe-Guard Study. JAMA Oncol 3(12):1733-1734. https://doi. org/10.1001/jamaoncol.2017.1346

28. Peterson SK, Pentz RD, Marani SK et al (2008) Psychological functioning in persons considering genetic counseling and testing for Li-Fraumeni syndrome. Psychooncology 17(8):783-789. https ://doi.org/10.1002/pon.1352

29. Lammens CR, Aaronson NK, Wagner A et al (2010) Genetic testing in Li-Fraumeni syndrome: uptake and psychosocial consequences. J Clin Oncol 28(18):3008-3014. https://doi.org/10.1200/ JCO.2009.27.2112

30. Lammens CR, Bleiker EM, Verhoef S et al (2011) Distress in partners of individuals diagnosed with or at high risk of developing tumors due to rare hereditary cancer syndromes. Psychooncology 20(6):631-638. https://doi.org/10.1002/pon.1951

31. Cook JV, Dickinson HO, Eccles MP (2009) Response rates in postal surveys of healthcare professionals between 1996 and 2005: an observational study. BMC Health Serv Res 9:160. https://doi. org/10.1186/1472-6963-9-160 